\title{
Globalización y Derecho: siete tesis
}

\section{Miguel Carbonell}

\section{Introducción}

La globalización parece ser un concepto que llegó para quedarse. No hay reunión de políticos o de académicos en donde al menos uno de los participantes no haga referencia a los «desafíos» o a los «retos" que supone la globalización. Lo que sucede, sin embargo, es que a dicha omnipresencia no le sigue la correspondiente omnicomprensión. Es decir, con frecuencia se habla de la globalización sin saber exactamente a qué se está haciendo referencia. ${ }^{1}$

Desde luego, intentar definir un proceso sumamente complejo como el que nos ocupa es una tarea que, con seguridad, no puede ser abordada

1 Ha sido Zygmunt Bauman quien ha llamado la atención sobre el uso poco meditado del término globalización; de acuerdo con este autor:

"La globalización está en boca de todos; la palabra de moda se transforma rápidamente en un fetiche, un conjuro mágico, una llave destinada a abrir las puertas a todos los misterios presentes y futuros. Algunos consideran que la globalización es indispensable para la felicidad; otros, que es la causa de la infelicidad. Todos entienden que es el destino ineluctable del mundo, un proceso irreversible que afecta de la misma manera y en idéntica medida a la totalidad de las personas [...].

Las palabras de moda tienden a sufrir la misma suerte: a medida que pretenden dar transparencia a más y más procesos, ellas mismas se vuelven opacas; a medida que excluyen y reemplazan verdades ortodoxas, se van transformando en cánones que no admiten disputa. Las prácticas humanas que el concepto original intentaba aprehender se pierden de vista, y al expresar "certeramente" los "hechos concretos" del "mundo real», el término se declara inmune a todo cuestionamiento. "Globalización" no es la excepción a la regla», Zigmunt Bauman, La globalización. Consecuencias humanas, FCE, México, 1999, p. 7. 
en forma individual. Sin embargo, creo que es posible ir fijando algunos puntos que nos pueden ayudar a entender mejor qué es y cómo se manifiesta la globalización, así como a cuestionar algunos de sus principales efectos. Ese es el objeto de las tesis o ideas que siguen.

\section{Siete tesis}

1. La globalización, en singular, no existe. Se simplifica para abreviar, pero a poco que se repare, cualquiera se dará cuenta que, en realidad, no hay una sino varias globalizaciones, cada una de las cuales obedece a su propia lógica y a sus propios ritmos.

Hay, por ejemplo, un proceso de globalización de las comunicaciones, auspiciado por el desarrollo de las tecnologías satelitales y por la difusión masiva del internet. ${ }^{2}$ Hay también una globalización financiera, producto de la interconexión de los mercados bursátiles en todo el mundo y de los alcances planetarios que hoy en día tienen los llamados global-players (que son fundamentalmente empresas transnacionales y agentes de inversión que operan a escala global). ${ }^{3}$ Hay, en fin, una globalización cultural, que se manifiesta sobre todo en la adopción de pautas culturales producidas

2 Manuel Castells, La era de la información. Economía, sociedad y cultura, vol. I (La Sociedad Red), Siglo XXI, México, 1999.

3 Hans Peter Martin y Harald Schumann, La trampa de la globalización, Taurus, Madrid, 1998. Para ilustrar con algunas cifras los avances que han tenido tanto el proceso de globalización de las comunicaciones como el que tiene que ver con la creación de mercados financieros interconectados que pueden operar a escala global, basta tener en cuenta lo siguiente: las llamadas internacionales de teléfono que en 1945 costaban 1 dólar, hoy en día cuestan solamente un centavo de ese mismo dólar. En Alemania, las llamadas al exterior pasaron de 127 millones en 1979 a 694 millones en 1989; en los Estados Unidos subieron de 170 millones hasta 835 millones; en Japón pasaron de 10 a 167 millones. La interconexión permanente de los mercados financieros permite que una institución efectúe como media entre tres mil y cuatro mil operaciones cambiarias en un día normal, cifra que aumenta hasta en un $50 \%$ en los días más intensos. Las cotizaciones de divisas, en parte como consecuencia simplemente de ese incesante intercambio, pueden alterarse unas veinte veces en sesenta segundos en el caso de las principales monedas, Ilegando a modificarse hasta 18.000 veces en un solo día. En días muy activos un solo corredor de bolsa o de divisas (un dealer) suele concluir una operación de entre 200 y 500 millones de dólares entre cada dos y cada cuatro minutos. Todos estos datos están tomados de José Eduardo Faria, El derecho en la economía globalizada, Trotta, Madrid, 2001, p. 55, nota 2, que a su vez se apoya en datos del GATT. 
en Estados Unidos y promovidas por todo el planeta; buena parte de los habitantes de la tierra vemos las mismas películas, las mismas series de televisión, nos informamos a través de las mismas agencias, seguimos los eventos deportivos que se llevan a cabo o se financian desde los Estados Unidos, etcétera. Más que de globalización en este último caso podría hablarse de "neocolonización", pues es solamente una de las partes la que está dominando el escenario cultural. ${ }^{4}$

Los impactos de las globalizaciones han sido distintos según los campos en los que han incidido y han cambiado también según los países a los que han afectado. Así por ejemplo, la globalización de los mercados financieros se ha dejado sentir menos en África que en Europa o en América del Norte, por la sencilla razón de que las posibilidades de inversión especulativa que tiene todo ese continente son considerablemente menores que la que tienen los demás.

2. Paradójicamente, la globalización genera no solamente prácticas supranacionalizadoras, sino también efectos disgregadores al interior de cada Estado nacional. De esta forma, la era de las empresas transnacionales como Disney o Microsoft se significa también por ser, a la vez, el tiempo de las minorías. ${ }^{5}$

La lógica segregacionista y la reivindicación de lo local se manifiesta lo mismo en Cataluña que en Kosovo, en Chiapas que en Irlanda del Norte. Luego de la caída del Muro de Berlín, como se ha encargado de recordar Daniel Bell, las energías culturalistas y nacionalistas se han intensificado. ${ }^{6}$

Algunos autores señalan este doble efecto de la globalización (hacia arriba, pero también hacia abajo) y sostienen que sería mejor hablar de "glocalización", para dar cuenta de la combinación de energías que señalan tanto hacia una efectiva supranacionalización (que incluye el desvanecimiento de las fronteras políticas o incluso físicas entre los países), como hacia una vuelta al localismo (en forma de desmembración de Estados, de movimientos secesionistas, de mayores demandas de autonomía política

4 Néstor García Canclini, La globalización imaginada, Paidós, México, 1999.

5 Benjamin Barber, Jihad vs. Mc World. How globalism and tribalism are reshaping the world, Ballantine Books, Nueva York, 1996; desde una óptica jurídica, Miguel Carbonell, «Minorías y derechos: un punto de vista constitucional», en: M. Carbonell, J. A. Cruz Parcero y Rodolfo Vázquez (compiladores), Derechos sociales y derechos de las minorías, $2^{\text {a }}$ edición, UNAM, Porrúa, México, 2001; idem, “El siglo de las minorías», en: Le Monde Diplomatique (edición mexicana), año 3, $\mathrm{N}^{\circ} 31$, enero-febrero de 2000.

6 "Las muchas facetas del siglo XX», en: Letras libres, N¹0, México, octubre de 1999. 
de las regiones, de políticas y reivindicaciones multiculturalistas, etcétera). ${ }^{7}$ El científico social Anthony Giddens lo explica con las siguientes palabras:

«La globalización es, pues, una serie compleja de procesos, y no uno solo. Operan, además, de manera contradictoria o antitética. La mayoría de la gente cree que la globalización simplemente "traspasa" poder o influencia de las comunidades locales y países a la arena mundial. Y ésta es, desde luego, una de sus consecuencias. Las naciones pierden algo del poder económico que llegaron a tener. Pero también tiene el efecto contrario. La globalización no solo presiona hacia arriba, sino también hacia abajo, creando nuevas presiones para la autonomía local. El sociólogo norteamericano Daniel Bell lo describe muy bien cuando dice que la nación se hace no solo demasiado pequeña para solucionar los grandes problemas, sino también demasiado grande para arreglar los pequeños». ${ }^{8}$

Para los ordenamientos jurídicos, este movimiento en doble dirección ha supuesto la necesidad de ir construyendo nuevos paradigmas, por ejemplo en lo relativo a los sujetos de los derechos fundamentales (las constituciones han recogido derechos de las minorías o de grupos vulnerables, derechos de las comunidades indígenas y derechos colectivos) o también en lo que se refiere a la organización y funcionamiento de los poderes públicos (mediante la creación de nuevos niveles de gobierno, mediante el reconocimiento de la capacidad jurídica de regulación de asociaciones vecinales, a través de la tutela del llamado "tercer sector", conformado por las organizaciones non-profit y así por el estilo).

Más lento ha sido el proceso de configuración jurídica de un orden jurídico supra-nacional, pues parte de la lógica que han impuesto las grandes empresas a los distintos procesos de globalización ha sido la de exigir a los gobiernos la más completa de las libertades para el movimiento de

7 En este sentido, Isidoro Moreno, «Mundialización, globalización y nacionalismos: la quiebra del modelo de Estado-nación”, en: M. Carbonell y R. Vázquez (compiladores), Estado constitucional y globalización, UNAM, Porrúa, México, 2001.

8 Anthony Giddens, Un mundo desbocado. Los efectos de la globalización en nuestras vidas, Taurus, Madrid, 2000, p. 25. 
capitales, lo que se ha traducido en una suerte de anarco-capitalismo mundial que ha hecho de la falta de reglas su nueva y particular grund-norm. ${ }^{9}$

A falta de una arquitectura institucional que esté a la altura de los problemas complejos que existen en la era de la globalización, algunos Estados que cuentan con el predominio tecnológico y militar han dando rienda suelta a iniciativas unilaterales, poniendo en riesgo la estabilidad, la seguridad y el futuro de buen número de los habitantes del planeta. Sobre esto se abunda en párrafos posteriores. Importa solamente señalar, de momento, que el movimiento doble que se ha generado en los tiempos recientes no ha logrado desplegar todavía un entramado normativo e institucional que sea capaz de poner en claro las reglas para todos los involucrados y que, en ese contexto, una serie importante de fenómenos y problemas nuevos no son objeto, en la actualidad, de regulación completa y eficaz.

3. El punto anterior presta fundamento a la posibilidad de que, asumiéndola como proceso complejo, la globalización se nos rebele no como un fenómeno objetivo del que no cabe escapar bajo ninguna circunstancia, sino como un proceso de ida y vuelta, de desplazamientos sobre múltiples pistas. La globalización sería, en muchos aspectos, una construcción ideológica, susceptible no solamente de una valoración en términos de eficiencia económica, sino también y sobre todo sujeta a un enjuiciamiento ético. ${ }^{10}$

Lo anterior es relevante para echar abajo la tesis que prevaleció durante la primera mitad de los años 1990 en el sentido de que no había alternativa alguna a la globalización y solo por mala fe o por necedad se podía cuestionar un proceso histórico imparable y sujeto a sus propias dinámicas. Frente a la afirmación de que no hay alternativa frente a los procesos globalizadores, hoy existe un pensamiento social y una serie de movimientos colectivos que propugnan ir modulando algunas de las manifestaciones más salvajes de la globalización. ${ }^{11}$

9 En este sentido, Luigi Ferrajoli, «Pasado y futuro del Estado de derecho", en: Miguel Carbonell, Wistano Orozco y Rodolfo Vázquez (coordinadores), Estado de derecho. Concepto, fundamentos y democratización en América Latina, UNAM - ITAM - Siglo XXI editores, México, 2002, p. 196.

10 En este sentido, Roberto Toscano, "Interrogantes éticos sobre la globalización", en: Estado constitucional y globalización, op. cit., p. 54.

11 Roberto Toscano, «Interrogantes éticos sobre la globalización», en: Estado constitucional y globalización, op. cit, p. 53 y ss. 
Así por ejemplo, hay un fuerte impulso para crear la llamada "Tasa Tobin" que suponga un leve desestímulo para la inversión financiera puramente especulativa. El apoyo a la Tasa Tobin implica reconocer que los mercados financieros no pueden operar de forma completamente libre, sin asumir los costos de ir alojándose en aquellos países que, cada día o cada minuto, les vayan ofreciendo mayores rendimientos. Los flujos de inversión deberían tener también incentivos para generar inversiones productivas y no meramente especulativas. Las inversiones productivas permiten crear empleos, construir viviendas y fábricas, financiar proyectos de desarrollo para las pequeñas y medianas empresas, etcétera. Nada de eso puede darse cuando los capitales entran y salen de los países en menos de cuarentiocho horas. ${ }^{12}$ Todavía en 1970 el $90 \%$ de las transacciones por flujos internacionales de capital estaba vinculado a la economía real (comercio e inversión a largo plazo); para 1995 el 95\% de esas transacciones era de carácter especulativo y su permanencia en los países de destino era muy corta (el $80 \%$ permanecía en ellos una semana o menos). ${ }^{13}$

Además de desincentivar las inversiones especulativas, si los ingresos que se obtengan por medio de la Tasa Tobin se destinan a la ONU, podría crearse un fondo especial para contingencias humanitarias, que serviría para evitar las peores formas de violación de los derechos humanos, tanto de los civiles y políticos (a través de la financiación de fuerzas de intervención rápida, que pudieran evitar masacres y genocidios), como de los sociales y económicos (por medio de la prevención de las hambrunas o de la asistencia de los refugiados).

De forma más general, incluso se puede ir pensando en la creación de una "fiscalidad mundial», que sirviera para financiar a las instituciones internacionales que actúan para garantizar los derechos fundamentales (la misma ONU en general, o la UNICEF, la FAO o la OMS en particular). Aparte de la ya mencionada Tasa Tobin, la fiscalidad mundial podría imponer tributos para resarcir el indebido enriquecimiento de las empresas de los países más desarrollados a través de la explotación, o incluso del daño, de los llamados «bienes comunes de toda la humanidad», como lo

12 Sobre la "Tasa Tobin", de entre la abundante información disponible, se puede ver Susana Merino, La tasa Tobin. Tres años de historia, ATTAC-Argentina, Buenos Aires, 2001; Alex C. Michalos, Un'imposta giusta: la Tobin tax, Turín, 1999.

13 Dato tomado de Noam Chomsky, Estados canallas. El imperio de la fuerza en los asuntos mundiales, Paidós, Barcelona, 2001, p. 137. 
son las órbitas satelitales, la composición atmosférica o los recursos de los fondos oceánicos, todos explotados actualmente como si fueran res nullius, cuando en realidad pertenecen a toda la humanidad y, en consecuencia, no pueden ser objeto de apropiación de ninguna empresa y de ningún Estado en particular. ${ }^{14}$

Si tomamos en cuenta los datos más recientes generados desde instancias de reconocida probidad y que recaban información con base en las más serias metodologías de la investigación social, todo parece indicar que tenemos un mundo claramente fragmentado, lo cual viene a corroborar la idea de una globalización desigualmente vivida y sufrida por los habitantes del planeta. Las cifras son espeluznantes. Algunas de ellas son las siguientes. ${ }^{15}$

A. Aunque ya en ciento cuarenta países del planeta se convocan elecciones en las que concurren varios partidos, solamente ochenta Estados pueden considerarse como plenamente democráticos (en ellos vive el $55 \%$ de la población mundial). En ciento seis países todavía se limitan las libertades civiles y políticas de sus habitantes. La democratización de los Estados como un requisito para poder contar con un espacio internacional igualmente democratizado todavía no es una tarea cumplida. ${ }^{16}$

B. Aún a pesar de su teórica inevitabilidad histórica y de los supuestos beneficios que en ella creen ver sus defensores, la globalización todavía no permite que los Estados dejen de matar a sus ciudadanos. En la década de 1990, tres millones seiscientos mil personas murieron en guerras dentro de los países (guerras internas, por tanto), frente a las veintidós mil personas que murieron en los conflictos entre países. La misma década vio un aumento del $50 \%$ en el número de refugiados y desplazados internos por los conflictos civiles vividos en sus países. En el curso del siglo XX, los gobiernos han provocado la muerte de unos ciento setenta millones de personas, cifra muy superior a la de las personas que murieron en las guerras entre Estados. La mitad de todas las personas que perdieron la vida en guerras fueron niños y se estima que, actualmente, hay 300.000 niños soldados en el mundo.

14 Luigi Ferrajoli, «Per una sfera pubblica del mondo», en: Teoria Politica, №3, Turín, 2001, p. 18.

15 Se toman de PNUD, Informe sobre desarrollo humano 2002. Profundizar la democracia en un mundo fragmentado, Mundi-Prensa, Madrid, 2002.

16 Informe sobre desarrollo humano, op. cit., p. 15. 
C. La pobreza y la desigualdad siguen marcando esta «era de la información": el ingreso del 1\% de la población más rica del planeta equivale al del $57 \%$ más pobre. El 10\% más rico de personas de Estados Unidos tiene tantos ingresos como el $43 \%$ de la población más pobre del mundo; esto supone que 25 millones de los estadounidenses más ricos suman tantos ingresos como casi los 2.000 millones de personas más pobres del orbe. La relación entre los ingresos del $5 \%$ más rico del mundo y el $5 \%$ más pobre es de 114 a 1 . Todavía 2.800 millones de personas sobreviven con menos de dos dólares al día. Una de las consecuencias inmediatas de la pobreza es el aumento de la mortalidad materna, mucho más alta en algunas regiones del mundo. ${ }^{17}$

D. Los medios de comunicación se habrán globalizado, pero las fuentes efectivas de información para los ciudadanos parecen estarse reduciendo a mucha velocidad, si atendemos al creciente fenómeno de virtual oligopolio que existe en los medios masivos alrededor del mundo. Estados Unidos e Inglaterra son buenos ejemplos de lo anterior: en el primero de esos países, seis empresas controlan la mayoría de los medios informativos; en Inglaterra cuatro empresas poseen el 85\% de los diarios de ese país. Y lo mismo, o algo muy parecido, se puede observar en otros países, como es el caso de México o de Italia. Sigue estando vigente la afirmación que hizo en 1944 Albert Camus: «La prensa es libre cuando no depende del poder del gobierno o del poder del dinero"; parece que en muchos países los medios de comunicación están transitando de un patrón a otro de los mencionados por Camus. Por otro lado, 61 países (en los que vive el $38 \%$ de la población mundial) carecen todavía de medios informativos libres y presentan importantes restricciones en los derechos a la libertad de expresión, de imprenta y de información.

E. El internet, que ya forma parte de la cotidianidad de los ciudadanos en muchos países avanzados, es todavía extraño para las personas en la mayoría de Estados. De hecho, el $72 \%$ de los usuarios de la red vive en países de la OCDE con alto nivel de ingresos, y representan apenas el $14 \%$ de la población mundial. 164 millones de esos usuarios viven en Estados Unidos.

4. La globalización permite que una señal de satélite pueda atravesar todo el planeta en cuestión de segundos y llegar hasta un aparato receptor se encuentre donde se encuentre. Las inversiones de capital, la compra-

17 Informe sobre desarrollo humano, op. cit., p. 27. 
venta de divisas, la transmisión electrónica de datos y las ondas de radio no se detienen ante ninguna patrulla fronteriza, ni deben cargar con pasaporte. No sucede lo mismo, sin embargo, con las personas, que no han visto en la globalización una oportunidad para poder mudar su lugar de residencia. O mejor dicho, sí que han tenido esa oportunidad en virtud de los avances en los transportes, pero frente a las posibilidades de movilidad que ofrecen las nuevas tecnologías, los Estados han contestado fortaleciendo sus controles fronterizos, endureciendo sus leyes migratorias y permitiendo retrógradas manifestaciones de xenofobia y racismo dentro de sus territorios. Roberto Toscano describe con mucho acierto el nuevo papel de los Estados en su tarea de reprimir la libre circulación de las personas, antes que la de las mercancías: «Incapaces ya de controlar los flujos del capital, la localización de las empresas, los tipos de cambio de la moneda, los Estados demuestran una patética crueldad compensatoria en el control de las fronteras, en la vigilancia de la entrada de los diversos, en la tentativa de excluirlos». ${ }^{18}$ Danilo Zolo ha afirmado, con razón, que la contestación de los Estados frente al fenómeno migratorio, que se concreta en expulsiones y persecuciones, o a través de la negación de la calidad de sujetos a los inmigrantes, «está escribiendo y parece destinada a escribir en los próximos decenios las páginas más luctuosas de la historia civil y política de los países occidentales". ${ }^{19}$

Una tarea pendiente para la globalización es universalizar la libertad de tránsito y de residencia, así como poner en cuestión la legitimidad que tienen los Estados (aunque yo creo que no la tienen) para cerrar sus fronteras a los no nacionales.

5. Uno de los significados más obvios de la globalización es el que tiene que ver con la existencia de un espacio público multilateral; es decir, con la presencia de una serie de actores de comparten la responsabilidad de la toma de decisiones, contrariamente a lo que sucedía antes del derrumbe del bloque soviético en donde eran dos países los que determinaban la actuación de los demás en virtud de sus intereses.

Sin embargo, luego de los lamentables acontecimientos del 11 de septiembre del 2001 y de las consecuencias que desencadenaron, la posibili-

18 Roberto Toscano, "Interrogantes éticos sobre la globalización", en: Estado constitucional y globalización, op. cit., p. 59.

19 Danilo Zolo, "La strategia della cittadinanza», en: Danilo Zolo (editor), La cittadinanza. Appartenenza, identitá, diritti, $2^{\text {a }}$ edición, Laterza, Roma-Bari, 1999, p. 42. 
dad de una dirección compartida y multilateral de los asuntos globales parece estar cediendo de forma acelerada para dar paso a la lógica unilateral que pretende imponer Estados Unidos, que se está tomando muy en serio su papel de imperio en los tiempos de la globalización. ${ }^{20}$ Parece urgente reivindicar, en este punto, el papel del sistema jurídico internacional y de la cooperación entre naciones para hacer frente a las amenazas globales a las que nos enfrentamos todos y denunciar las profundas injusticias que se esconden bajo el concepto de "guerra justa", que el imperio quiere librar contra los bárbaros en el exterior y contra los rebeldes en el interior de sus fronteras. ${ }^{21}$

La misma urgencia tiene denunciar públicamente, exhibir y cuestionar a los que Chomsky ha llamado "Estados canallas", con Estados Unidos a la cabeza; de acuerdo con este autor, son "Estados canallas" los que "no se consideran obligados a actuar de acuerdo con las normas internacionales». ${ }^{22}$ Las tendencias unilateralistas de Estados Unidos en la política internacional ciertamente se han visto reforzadas luego de la llegada al poder del Presidente George W. Bush y todavía más con los hechos del 11 de septiembre, pero ya existían en los años precedentes. Incluso la administración Clinton informó en 1993 a la ONU que «actuará multilateralmente cuando sea posible, pero unilateralmente cuando sea necesario». En 1999 el entonces Secretario de Defensa, William Cohen sostuvo que Estados Unidos estaba dispuesto a hacer un «uso unilateral del poder militar» para defender (sus) intereses vitales, los que incluyen «asegurar el acceso sin obstáculos a mercados clave, aprovisionamiento de energía y recursos estratégicos». ${ }^{23}$

Para repotenciar los diálogos multilaterales es indispensable la generación de una esfera pública global, que pueda operar dentro y fuera de las instituciones formales, que contribuya a nutrir un debate que actualmen-

$20 \mathrm{Al}$ respecto, Michael Hardt y Antonio Negri, Imperio, Paidós, Barcelona, 2002.

21 Tomo la idea de Hardt y Negri, quienes afirman lo siguiente: «El concepto de imperio se presenta como un concierto global bajo la dirección de un único conductor, un poder unitario que mantiene la paz social y produce sus verdaderas éticas. Y para que ese poder único alcance tales fines, se le concede la fuerza indispensable a efectos de librar - cuando sea necesario- "guerras justas», en las fronteras, contra los bárbaros y, en el interior, contra los rebeldes» (p. 27).

22 Estados canallas, op. cit., p. 9.

23 Citas tomadas de Chomsky, op. cit, p. 13. 
te es bastante pobre y que sirva como marco de reflexión para generar nuevas pautas de acción política. ${ }^{24}$ Dicha esfera pública global, además, podría contraponerse a la lógica del mercado, ese sí global en muchos aspectos, que actualmente está colonizando parcelas cada vez más importantes de la vida de millones de personas y que amenaza con sustituir la plaza pública y el intercambio de opiniones por el centro comercial y las tarjetas de crédito.

El reforzamiento de la esfera pública mundial tiene como condición previa afirmar el principio del monopolio del uso de la fuerza a nivel internacional, el cual debe residir únicamente en la ONU. Junto con ello, es importante desarmar a los Estados, de forma que se eviten reacciones armadas unilaterales en violación a la Carta de la ONU. Para lograrlo, se debe vigilar y sancionar a los Estados que sigan fabricando y exportando armas. ${ }^{25}$

6. Una de las esperanzas más fundadas de que la globalización no sirva como parapeto de la extensión universal del imperio es el movimiento anti-globalizador que se ha ido estructurando, de forma más o menos desordenada, en los últimos años. Aunque parezca paradójico, es de ese movimiento, de donde pueden salir algunas de las correcciones que deben hacerse al proceso de globalización.

Por desgracia, sin embargo, los Estados se han apurado a criminalizar el movimiento y a reprimirlo tanto por vías legales como ilegales. Los medios de comunicación han jugado un doble papel con respecto a la movilización anti-globalizadora: por un lado, le han dado al movimiento una interesante cobertura mediática, lo que ha permitido que sus acciones y sus ideas hayan llegado a amplios espectros de la opinión pública; pero por otro lado, muchas veces los medios se han concentrado en los actos del sector más radical del movimiento, que ha incurrido o ha sido provocado para incurrir en sucesos de vandalismo.

24 Ver las reflexiones de Luigi Ferrajoli, «Peruna sfera pubblica del mondo», en: op. cit., pp. 3-21.

25 En la actualidad, la mayor parte de las exportaciones mundiales de armas la hacen los Estados Unidos y Rusia, seguidos de Francia y el Reino Unido. Entre 1996 y 2001 los Estados Unidos exportaron armas por un valor de 54,000 millones de dólares, Rusia lo hizo por un valor de 21,000 millones de dólares, Francia por 11,000 millones de dólares y el Reino Unido por 8,000 millones de dólares. La información de toma del Informe sobre Desarrollo Humano 2002, presentado por el PNUD, p. 89. 
La presentación de los anti-globalizadores como simples agitadores o como profesionales de la protesta no ha contribuido a fomentar la atención reflexiva sobre un movimiento que defiende ideas interesantes e importantes y que, además, supone la cabeza visible de las manifestaciones de impotencia y angustia que sienten millones de personas frente a un proceso globalizador que está acabando con sus fuentes de trabajo y que amenaza con reducir drásticamente su nivel de vida en los países desarrollados o con impedir acceder al desarrollo en los países periféricos.

De hecho, algún autor como Luigi Ferrajoli ha señalado la paradoja de que es justamente el movimiento anti-globalización el que más lucha en favor de una globalización no solamente de las mercancías, sino también de los derechos. Mientras que serían los Estados más ricos del planeta (los que conforman el llamado G-8) los que más se opondrían al desarrollo de la globalización al reducirla con toda intencionalidad a un sentido puramente económico, basado en la ley del más fuerte que se impone ante la ausencia de reglas de alcance planetario para dominar a los emergentes poderes económicos. ${ }^{26}$

7. Ante todos los factores y nuevos condicionamientos que se acaban de mencionar, es obvio que también el sistema jurídico se ha modificado con alguna profundidad. Son muchos los ejemplos y las manifestaciones que se podrían citar; menciono solamente uno de ellos de alcances no coyunturales sino, en mi opinión, estructurales.

Se puede afirmar con alguna contundencia que parecen estarse borrando o al menos difuminando las fronteras entre el derecho nacional y el derecho internacional. ${ }^{27}$ Cada vez son más los puntos de intersección y cada vez más las necesidades de los juristas de manejarse con soltura en los dos niveles normativos. Así por ejemplo, un experto en derecho mercantil tiene que conocer lo mismo el código de comercio o la ley de sociedades mercantiles, que los tratados de libre comercio que tiene firmados México con un número importante de naciones o incluso de bloques de países (como la Unión Europea); de la misma forma, un penalista debe

26 "Per una sfera pubblica del mondo», op. cit., p. 16 y 17.

27 Lo cual quizá sea una consecuencia de la evaporación de las fronteras entre la "política interna" de los Estados y la política internacional; algunos autores, señalando este fenómeno, defienden la necesidad de comenzar a pensar en una "política interna del mundo". Ver al respecto, las observaciones de Ferrajoli, "Per una sfera pubblica del mondo", op. cit., pp. 3-7. 
estar al tanto de los desarrollos de la justicia penal internacional ${ }^{28}$ (la Corte Penal Internacional o, en algunos aspectos, la Corte Interamericana de Derechos Humanos) y de los tratados de extradición vigentes en el país, tanto como de las reformas al código penal; igualmente, un constitucionalista no puede agotar su estudio de los derechos fundamentales en los contenidos de la primera parte de la Constitución, sino que debe conocer también los tratados internacionales de derechos humanos, así como la jurisprudencia, las opiniones consultivas y las observaciones generales que periódicamente emanan de diversos tribunales y organismos internacionales. Además, desde un punto de vista estructural, son abundantes los textos constitucionales que reconocen una jerarquía preeminente a los tratados internacionales de derechos humanos, ${ }^{29}$ incluso de rango constitucional, tendencia hacia la que debería caminar de manera decidida México. ${ }^{30}$ En este contexto, la creación de jurisdicciones supranacionales obliga a los tribunales nacionales a manejarse con diligencia en el derecho internacional, para el efecto de evitar una condena por aquellos contra el Estado mexicano por violación de una de sus obligaciones internacionales.

\section{A modo de conclusión}

En suma, lo que tenemos frente a nosotros es un panorama sumamente complejo, sobre cuyos problemas deben estar advertidos los científicos sociales. Pero de esa complejidad y de esa problemática tan ardua no puede derivarse un llamamiento a la simple contemplación. Por el contrario, hoy las ciencias sociales y concretamente la ciencia jurídica tienen sobre sus espaldas la enorme responsabilidad de imaginar rutas alternativas y de ofrecer debates que cuestionen los efectos más negativos de la globalización.

28 Un buen panorama de síntesis sobre el tema se puede encontrar en Sergio García Ramírez, La Corte Penal Internacional, INACIPE, México, 2002.

$29 \mathrm{Al}$ respecto, Carlos $\mathrm{M}$. Ayala Corao, "La jerarquía constitucional de los tratados relativos a derechos humanos y sus consecuencias», en: Ricardo Méndez Silva (coordinador), Derecho internacional de los derechos humanos. Memoria del VII Congreso Iberoamericano de Derecho Constitucional, IIJ-UNAM, México, 2002, p. 37 y ss.

$30 \mathrm{Al}$ respecto, Miguel Carbonell, La Constitución pendiente. Agenda mínima de reformas constitucionales, IIJ-UNAM, México, 2002, capítulo II. 
De la misma forma, la ciudadanía no puede ni debe permanecer pasiva, esperando que las soluciones lleguen de los gobiernos o de las instituciones internacionales. La respuesta a muchos problemas sigue estando, hoy como ayer, en nuestras manos. Pero esa solución requiere de una sociedad alerta, permanentemente crítica y movilizada, capaz de hacer valer sus derechos en, fuera e incluso contra los órganos estatales e internacionales. No se trata de otra cosa más que de volver a los inicios del constitucionalismo y recuperar el sentido del artículo $23^{\circ}$ de la Constitución francesa del año $I$, de acuerdo con el cual «la garantía social consiste en la acción de todos para asegurar a cada uno el disfrute y la conservación de sus derechos". ${ }^{31}$

Ni los ciudadanos, ni mucho menos los científicos sociales, pueden desatender las responsabilidades señaladas argumentando que frente a la complejidad de los problemas es muy poco lo que puede hacerse y que muchas de las alternativas que se señalan a la globalización son simplemente utópicas, lo cual haría inviable cualquier intento de respuesta teórica. Como señala Ferrajoli, hay que distinguir entre los problemas políticos y los problemas teóricos. No se puede presentar como utópico o irrealista lo que simplemente no se quiere hacer porque no conviene a ciertos intereses políticos dominantes y que, en esa virtud y solamente por ella, presumiblemente no se hará. No hay que confundir realismo con conformismo, pues este segundo sirve solamente para legitimar y apoyar como algo inevitable lo que obviamente es obra de las personas, sobre el cual tienen una buena parte de responsabilidad los poderes políticos y económicos que son, hoy en día, hegemónicos. ${ }^{32}$

\section{Orientación bibliográfica}

La bibliografía sobre la globalización es literalmente inabarcable; en los últimos años el número de libros, ensayos, artículos en revistas y en

31 Sobre esto, Miguel Carbonell y Gerardo Pisarello, «La aplicación de los tratados internacionales de derechos humanos en el derecho interno: modelo para armar», en $\mathrm{Mi}$ guel Carbonell, Sandra Moguel y Karla Pérez Portilla (compiladores), Derecho Internacional de los Derechos Humanos. Textos Básicos, CNDH, Porrúa Hermanos, México, 2002, pp. 19 y 20.

32 "Per una sfera pubblica del mondo", op. cit., p. 18. 
periódicos que han abordado el tema suma millares de referencias. A continuación se incluye una breve lista -de carácter orientador- de títulos que abordan con detalle algunas de las cuestiones que en las páginas precedentes se han tratado de manera superficial. Se ha privilegiado la inclusión de textos recientes y escritos en castellano, aunque también se han incluido algunos en otros idiomas.

Antón, Antonio (coordinador), Trabajo, derechos sociales y globalización. Algunos retos para el siglo XXI, Talasa ediciones, Madrid, 2000.

Badie, Bertrand, Il mondo senza sovranitá, Asterios, Trieste, 2000.

Barber, Benjamin, Jibad vs. McWorld. How globalism and tribalism are reshaping the world, Ballantine Books, Nueva York, 1996.

Bauman, Zygmunt, La globalización. Consecuencias humanas, FCE, México, 1999.

Bell, Daniel, "Las muchas facetas del siglo XX», en: Letras libres, $\mathrm{N}^{\circ} 10$, México, octubre de 1999.

Beck, Ulrich, ¿Qué es la globalización?, Paidós, Barcelona, 1998.

Bonanate, Luigi, Democrazia tra le nazioni, Bruno Mondadori, Milán, 2001.

Carbonell, Miguel y Vázquez, Rodolfo (compiladores), Estado constitucional y globalización, IIJ-UNAM, Porrúa, México, 2001.

Carbonell, Miguel, Cruz Parcero, Juan Antonio y Vázquez, Rodolfo (compiladores), Derechos sociales y derechos de las minorías, $2^{a}$ edición, IIJ-UNAM, Porrúa, México, 2001.

Carbonell, Miguel, Orozco, Wistano y Vázquez, Rodolfo (coordinadores), Estado de derecho. Concepto, fundamentos y democratización en América Latina, UNAM - ITAM - Siglo XXI editores, México, 2002.

Carbonell, Miguel; Moguel, Sandra y Pérez Portilla, Karla (compiladores), Derecho Internacional de los Derechos Humanos. Textos básicos, Porrúa, CNDH, México, 2002.

Carrillo Salcedo, Juan Antonio, Soberanía de los Estados y derechos humanos en derecho internacional contemporáneo, Tecnos, Madrid, 2a edición, 2001.

Castells, Manuel, La era de la información. Economía, sociedad y cultura, 3 tomos, Siglo XXI, México, 1999.

Capella, Juan Ramón (coordinador), Transformaciones del derecho en la mundialización, CGPJ, Madrid, 1999.

Chomsky, Noam, Estados canallas. El imperio de la fuerza en los asuntos mundiales, Paidós, Barcelona, 2001. 
Faria, José Eduardo, El derecho en la economía globalizada, Trotta, Madrid, 2001.

Fariñas, María José, Globalización, ciudadanía y derechos humanos, Universidad Carlos III de Madrid - Dykinson, Madrid, 2000.

Fernández García, Eusebio, Dignidad humana y ciudadanía cosmopolita, Universidad Carlos III de Madrid, Dykinson, Madrid, 2001.

Ferrajoli, Luigi, "Per una sfera pubblica del mondo», en: Teoria Politica, número 3, Turín, 2001.

Ferrajoli, Luigi y otros, Los fundamentos de los derechos fundamentales, Trotta, Madrid, 2001.

Ferrarese, Maria Rosaria, Le istituzioni della globalizzazione. Diritto e diritti nella societá trasnazionale, Il Mulino, Bolonia, 2000.

García Canclini, Néstor, La globalización imaginada, Paidós, México, 1999.

García Ramírez, Sergio, La Corte Penal Internacional, INACIPE, México, 2002.

Giddens, Anthony, Un mundo desbocado. Los efectos de la globalización sobre nuestras vidas, Taurus, Madrid, 2000.

Habermas, Jürgen, La constelación posnacional, Paidós, Barcelona, 2000. Hardt, Michael y Antonio Negri, Imperio, Paidós, Barcelona, 2002.

Ianni, Octavio, La era del globalismo, Siglo XXI editores, México, 1999.

Innerarity, Daniel, La transformación de la política, Península, Barcelona, 2002.

Kaplan, Marcos, Estado y globalización, IIJ-UNAM, México, 2002.

Kaplan, Marcos e Irma Manrique (editores), Regulación de flujos financieros internacionales, IIJ-UNAM, IIE-UNAM, México, 2000.

Klein, Naomi, No logo. El poder de las marcas, Paidós, Barcelona, 2001.

Martin, Hans Peter y Harald Schumann, La trampa de la globalización, Taurus, Madrid, 1998.

Merino, Susana, La tasa Tobin. Tres años de historia, ATTAC-Argentina, Buenos Aires, 2001.

Michalos, Alex C., Un'imposta giusta: la Tobin tax, Turín, 1999.

Orozco, José Luis y Consuelo Dávila (compiladores), Breviario político de la globalización, Fontamara - UNAM, México, 1997.

Ortega, Andrés, Horizontes cercanos. Guía para un mundo en cambio, Taurus, Madrid, 2000.

Ovejero, Félix, La libertad inhóspita. Modelos humanos y democracia liberal, Paidós, Madrid, 2002.

PNUD, Informe sobre desarrollo humano 2002. Profundizar la democracia en un mundo fragmentado, Mundi-Prensa, Madrid, 2002.

Sen, Amartya, «Juicios sobre la globalización», en: Fractal, No 22, México, julio-septiembre de 2001. 
Desarrollo y libertad, Planeta, México, 2000.

Vallespín, Fernando, El futuro de la política, Taurus, Madrid, 2000.

Vidal Beneyto, José (director), La ventana global, Taurus, Madrid, 2002.

Zolo, Danilo, Cosmópolis. Perspectiva y riesgos de un gobierno mundial, Paidós, Barcelona, 2000. 